\title{
Corrigendum: Personality as predictor of customer service centre agent performance in the banking industry: An exploratory study
}

\author{
Authors: \\ Linda Blignaut ${ }^{1}$ \\ Leona M. Ungerer ${ }^{1}$ \\ Helene Muller ${ }^{2}$ \\ Affiliations: \\ ${ }^{1}$ Department of Industrial \\ and Organisational \\ Psychology, University of \\ South Africa, South Africa \\ ${ }^{2}$ School of Interdisciplinary \\ Research and Graduate \\ Studies, CGS, University of \\ South Africa, South Africa

\section{Correspondence to:} \\ Linda Blignaut

\section{Email:} \\ lindab@jse.co.za
}

\section{Postal address:}

73 Cambridge Street,

Farrarmere, Benoni 1501,

South Africa

Dates:

Published: 19 Dec. 2014

How to cite this article:

Blignaut, L., Ungerer,

L.M., \& Muller, H. (2014).

Corrigendum: Personality as

predictor of customer service

centre agent performance

in the banking industry:

An exploratory study. SA

Journal of Human Resource

Management/SA Tydskrif vir

Menslikehulpbronbestuur,

12(1), Art. \#607, 1 page.

http://dx.doi.org/10.4102/

sajhrm.v12i1.607-1

Note:

Doi of original article: http:// dx.doi.org/10.4102/sajhrm. v12i1.607

\section{Copyright:}

(C) 2014. The Authors.

Licensee: AOSIS

OpenJournals. This work

is licensed under the

Creative Commons

Attribution License.

Read online:

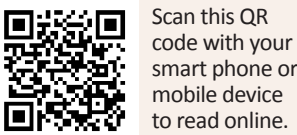

The authors apologise for omitting the third author's name from their article, Personality as predictor of customer service centre agent performance in the banking industry: An exploratory study, published 29 October 2014.

A third author, Helene Muller, has now been added to the article. For more information please see the updated authors' contributions section, which reflects the authors' role in the article:

\section{Authors' contributions}

L.B. (University of South Africa) was the main researcher responsible for the intellectual conceptualisation of the article, the development of the research design, data collection, and part of the data analysis. L.M.U. (University of South Africa) supervised the research, made conceptual contributions to the study and co-wrote the article. H.M. (University of South Africa) assisted in addressing the reviewers' comments and undertook additional statistical analyses. She contributed to the research objectives, added the statistical analysis strategy and wrote the results and conclusion sections of the final article. L.B. and L.M.U addressed the editor's and copy editor's concerns. 


\section{Personality as predictor of customer service centre agent performance in the banking industry: An exploratory study}

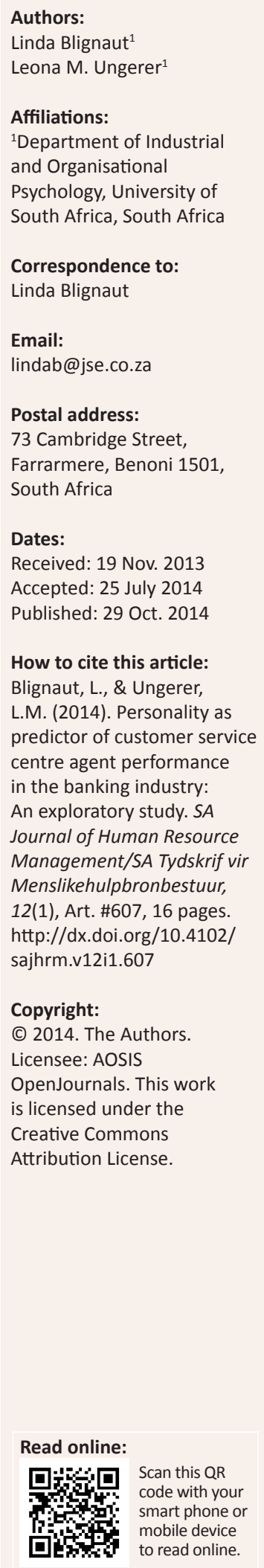

Orientation: Since service quality is an important differentiator in the banking industry, it is essential to select suitable customer service centre staff, particularly those who are responsible for handling queries from clients who hold significant lifetime value in this industry.

Research purpose: The aim of the study was to identify personality traits, as measured by the Occupational Personality Questionnaire 32r (item response theory scored version), including the more parsimonious Big Five personality traits, that may act as job performance predictors for customer service centre (CSC) agents in the banking industry.

Motivation for the study: This study provides an exploratory investigation of whether specific personality traits differ amongst CSC agents in the banking industry, based on their job performance. No published research in this field could be identified.

Research design, approach and method: Purposive sampling was used to collect data from the entire CSC agent base of a particular banking group $(N=89)$. Responses were analysed by means of quantitative techniques.

Main findings and practical/managerial implications: Results indicate that parsimonious traits of personality, expressed as the Big Five personality traits, predict job performance. The importance of carefully selecting suitable job performance criteria for a specific environment, however, emerged as a critical issue in performance prediction.

Contribution: The study focuses attention on the importance of CSC agents' performance as frontline staff in the banking industry and identifying valid criteria for selecting the most suitable agents. Providing a one-contact point of service such as a CSC is a fairly new approach in the South African banking industry and this study provides an initial investigation of personality traits that may serve as job performance predictors in this environment.

\section{Introduction}

\section{Key focus of the study}

The valuation of customers is gaining importance in the retail banking industry (Haenlein, Kaplan \& Beeser, 2007). This development supports a central idea in customer relationship management, namely that since customers vary in terms of their needs and the value they generate for a firm, they may have to be managed accordingly. Clients who hold significant lifetime value in the banking industry warrant special consideration, and since staff interacting with them may require distinctive qualities, this need to be considered in selecting suitable frontline staff members who deal with them. A number of meta-analyses substantiate the value of personality measures in selection (Tett \& Burnett, 2003), whilst additional meta-analyses suggest that personality measures may predict job performance quite well in particular settings (e.g. Barrick \& Mount, 1991; Salgado, 1997).

As far as could be determined, limited research has investigated the personality requirements of staff manning a customer service centre (CSC) in the banking industry. No relevant published research on the relationship between CSC agents' personality and their job performance within the South African banking industry could be found, pointing to a need for the current study. It serves as an exploratory investigation of whether specific personality traits differ amongst CSC agents in the banking industry, based on their job performance.

\section{Potential value-add}

Sawyer, Srinivas and Wang (2009) recommend investigating the relationship between personality factors and performance in the context of a customer relations management call 
centre environment in more depth. Huysamen (2002) also suggests ongoing research on assessment tools within the South African context. To this end, the researchers set out to investigate the relationships between the personality traits of CSC agents and their job performance in the banking industry using a well-established personality measure in South Africa: the Occupational Personality Questionnaire 32r (OPQ32r).

This research particularly contributes to an area of research related to call centre work that has received minimal research attention, namely the relationship between the individual characteristics of call centre employees (for instance, their personality characteristics) and their job performance (Sawyer et al., 2009). The selection of suitable staff or staff whose personality types meet the job requirements can potentially reduce absenteeism and turnover and have a positive link to customer service delivery (O'Hara, 2001).

Ones, Dilchert, Viswesvaran and Judge (2007) indicate that future research should continue exploring the potential for self-report ratings of personality in personnel selection, placement and promotion decisions. Identifying the personality characteristics of individuals who are successful in its CSC environment may assist the banking group to create a better fit between employees and the requirements of this type of environment. This, in turn, may improve organisational outcomes through improving the quality of the organisation's customer service and reducing the financial and human costs associated with poor service performance, poor attendance rates, high turnover rates and the cost of ineffective assessments.

\section{Background to the study}

Service quality is a critical factor for survival in the banking industry since it enhances customer satisfaction, improves customer retention and establishes a favourable overall image for financial institutions. It further significantly improves financial performance in terms of interest margins, return on assets, profit per employee and capital adequacy (Ladhari, 2009).

Ladhari (2009) advises that bank managers should recognise the crucial role that frontline employees play in establishing and maintaining a competitive position for their institutions. In light of their extensive influence, these employees should be recruited carefully, properly trained and motivated and supported by means of suitable recognition and incentive schemes. Customers' perceptions of companies are especially determined by the quality of their interaction with the companies' frontline employees in call centres (Mattila \& Mount, 2003; Subramaniam, 2008).

The banking group in which this study was conducted made the transition from a call centre to a contact centre or, as termed in the organisation, a CSC. The CSC caters exclusively for the needs of business and corporate clients whose annual turnover reaches billions of Rand and who typically fulfil an essential role in the long-term success of a banking group. Client segment teams in the CSC respond to incoming calls and emails from clients who are grouped according to their annual expenditure with the banking group. Each team provides technical information, solutions and support on a number of products, such as Internet banking, to their particular client segment.

The CSC agents assist clients at two help desks. The outputs of these help desks are the same; more experienced agents are simply promoted to help desk 2 when they are believed to be ready for this process. The better performing agents employed at help desk 2 are regarded as senior CSC agents and they assist high expenditure clients in the particular banking group.

The CSC staff turnover rate in the participating banking group was $29 \%$ during 2009 , dropping slightly to $27 \%$ in 2010. According to Barnes (2001), the high turnover rate that is endemic in the call centre industry is exacerbated by recruiting staff with the wrong personality type or whose personality types do not meet job requirements. O'Hara (2001) further points out that selecting suitable staff or staff whose personality types meet job requirements may reduce high absenteeism and turnover rates and enhance service delivery.

\section{Research objective}

The objective of this study is to explore the relationship between CSC agents' personality and their job performance in the banking industry. If parsimonious measures of personality (e.g. Big Five traits) can be derived from the OPQ32r scores in this exploratory study and statistically significant personality trait to performance criteria relationships may be identified for CSC agents, these relationships may be investigated in more depth in extended studies in the banking industry.

\section{Literature review}

\section{Call centres versus contact centres}

Call centres have emerged due to a changing world of work and the need to improve efficiency and customer service delivery. In a call centre, according to Holman (as cited in Janse van Rensburg, Boonzaier \& Boonzaier, 2013), the use of computer and telephone-based technologies enables the effective distribution of incoming and outgoing calls amongst available staff. Since call centre agents use display screen equipment to instantly access and capture information, customer-employee interaction takes place concurrently. Two traditional types of call centre exist. Inbound call centres typically handle incoming calls, responding to matters such as customers' complaints, requests and questions. Outbound call centres mainly focus on establishing contact with customers, supporting organisations in the sales of products or services.

The traditional call centre role, however, is shifting from being a cost centre to becoming a strategic business unit 
(Merchants, 2006). A systematic integration of multiple communication channels led to call centres merging into contact centres, serving as service centres to both customers and other organisational stakeholders (Langley, Fjalestad, Fichtner \& Hart, 2006). Contact centres particularly generate value by building relationships with customers, driving business processes, promoting the image of companies and building brand (Adria \& Chowdhury, 2004).

Contact centres play an essential role in modern organisations, responding to inbound requests and performing outbound sales and marketing over multiple channels. Contact centres often function as the sole points of contact between organisations and their stakeholders (mainly customers), playing a vital role in influencing customers' experience and promoting company culture. The top strategic issues for contact centres are currently customer satisfaction, quality and process improvements and technology strategy (Merchants, 2006).

There are several differences between a conventional call centre and the CSC operating at the bank where the current study was conducted. The contact centre industry has adopted first call resolution as a key performance indicator, representing efficiency and competence in satisfying inbound customer requests (Merchants, 2006). The particular CSC provides a one-contact experience to clients and a particular client's problem or request should be resolved during one interaction. Instead of merely using the call duration recorded and how efficiently an agent dealt with call requirements in the shortest time period, CSC team leaders also consider clients' experiences in terms of satisfactory problem or query resolution as measure of agents' job performance.

It is essential to attract and retain high-performing contact centre employees, and it is therefore of importance to a banking group to determine valid selection criteria for CSC agents.

\section{Personality and job performance Personality traits}

The personality measure used in the present study, the OPQ32r, was developed based on the trait theory of personality.

Although personality traits are central constructs in psychology, they are defined in various ways. Tett and Guterman (2000, p. 398, as cited in Tett \& Burnett, 2003) describe personality traits as 'intra-individual consistencies and inter-individual uniquenesses in propensities to behave in identifiable ways in light of situational demands'. According to Tett and Burnett (2003), this definition reflects five fundamental ideas underlying personnel selection and performance prediction:

- Since most people show a degree of intra-person consistency, it is possible to predict their future behaviour based on their past behaviour.

- Human uniqueness reflects consistent inter-person differences, creating the need to describe particular traits and leading to some people being hired instead of others.
- Personality traits are covert and it is essential to understand what activates them in order to understand the role of personality in work behaviour.

- Traits are inferred from overt behaviour.

- The expression of traits tends to be context dependent, and relevant situational features need to be considered in this regard.

\section{Five-factor theory of personality}

A fundamental issue in personality research is how many dimensions describe individual differences in personality (Van der Linden, Te Nijenhuis \& Bakker, 2010). Researchers address this matter by identifying hierarchical models consisting of higher-order clusters incorporating relevant behavioural measures. A widely accepted example of such a hierarchical model is the Big Five (Digman, as cited in Van der Linden et al., 2010), which includes the following dimensions: openness to experience, conscientiousness, extraversion, agreeableness and neuroticism. The five-factor theory is based on the idea that personality consists of a number of relatively independent dimensions that form a taxonomy by which individual differences can be explained (Visser \& Du Toit, 2004).

The above five factors explain and predict individual differences in a number of areas including mental health, job satisfaction and job performance (Barrick \& Mount, 1991; Judge, Heller \& Mount, 2002).

\section{Job performance}

Campbell (1990, p. 704) defines job performance (the dependent variable in this research) as 'those actions or behaviours relevant to the organisation's goals'. He also distinguishes between performance (the behaviours), effectiveness (the evaluation of the results of performance) and productivity (the cost of getting to certain levels of effectiveness).

Job performance is an individual level variable, that is, performance is something a single person does (Campbell, 1990). Job performance consequently is the total expected value to the organisation of the individual behavioural episodes over a standard period of time (Motowidlo, 2003). Motowildo, Borman and Schmit (1997) describe job performance as a behavioural construct and state that behaviour, job performance and results are not the same. Behaviour is what people do whilst at work. Performance is behaviour with an evaluative component; it is viewed as behaviour that can be evaluated as positive or negative for individual or organisational effectiveness. Results are states or conditions of people or things that are changed by performance and consequently either contribute to or detract from organisational goal accomplishment. Results are the route through which an individual's performance helps or hinders an organisation in reaching its goals, and this is what makes it appealing to focus on results when considering individual performance (Motowildo et al., 1997). 


\section{Concerns about the role of personality measures in predicting job performance}

The suitability of personality measures in predicting job performance has been debated for decades. Doubts about their aptness largely were based on mixed validity evidence, varying views about the underlying structure of personality and concerns about appropriate performance criteria (Skyrme, Wilkinson, Abraham \& Morrison, 2005).

Improved meta-analytic techniques and the establishment of the Big Five model of personality, however, renewed interest in personality as a selection measure (Penney, David \& Witt, 2011). The Big Five model particularly served to organise research findings and formulate research hypotheses (Skyrme et al., 2005).

Despite a considerable body of empirical evidence indicating that the Big Five model explains significant variance in job performance criteria, some concern exists about low reported validities. Researchers such as Tett and Christiansen (as cited in Penney et al., 2011), for instance, suggest that trends such as low reported validity and concerns about possibly faking responses prohibit the use of personality tests in selection contexts.

A meta-analysis of research on the relationship between personality and job performance, however, suggested that personality measures are valid predictors of diverse jobrelated criteria and typically do not have an adverse impact on disadvantaged employees who may not be test-wise or familiar with assessment situations (Barrick \& Mount, 1991; Hogan, Hogan \& Roberts, 1996). Tett and Christiansen (2007) and Ones et al. (2007) further emphasise that personality measures may enhance fairness in personnel decisions.

All in all, the relationship between people's personality traits and their job performance appears to be well established (Barrick \& Mount, 1991; Sawyer et al., 2009), but contradictory views about this relationship are evident in the literature.

To explain the fairly low validities associated with the Big Five and to contribute towards an understanding of the relationship between personality and behaviour, Penney et al. (2011) focus on three areas, namely the need to properly define the criterion domain, to consider situational moderators of the personality-performance relationship and to consider the impact of varying levels of a particular trait.

\section{Performance criteria}

To empirically validate the Big Five, it is essential to accurately define job performance criteria. This requirement incorporates both measurement and conceptual issues. Criterion measures should be reliable and valid and they should fully reflect essential performance requirements of the particular job (Penney et al., 2011).

Campbell, Gasser and Oswald (as cited in Penney et al., 2011) recommend that job performance should reflect both global measures of job performance and specific dimensions or facets of performance. Penney et al. (2011) point out three broad dimensions of overall job performance: task performance, contextual performance and counterproductive behaviour. Relationships between the Big Five traits and all three job performance dimensions have been established in existing research. The Big Five, however, more validly predict job performance when combined than separately (Judge, Heller, \& Mount, as cited in Penney et al., 2011).

Penney et al. (2011) highlight three trends escalating the need for expanding job performance criteria: an increase in service jobs (and the related need for interpersonal effectiveness), the increased necessity of teamwork in accomplishing tasks and an increasingly complex, changing modern workplace. Employees' personalities may determine their ability to adapt both behaviourally and psychologically to changing situations. The validity of the Big Five in predicting job performance may therefore be enhanced by incorporating performance measures that reflect service and adaptive behaviours and not merely broad job performance measures.

\section{Situational moderators}

Tett and Burnett (2003) recommend enhancing the suitability of personality measures in selection by considering theoretical bases of personality trait-performance linkages. Theoretical links between the traits and demands of a particular job should be investigated based on a job analysis (Tett et al., as cited in Penney et al., 2011).

Tett and Burnett (2003) further point out an occasionally overlooked trend in Barrick and Mount's (1991) metaanalytic study (which identified trait-performance relations for a variety of job families based on the Big Five). Situational specificity is evident right through Barrick and Mount's groups, even in cases where the mean validity was quite high. The direction of validity may further vary in traitjob combinations and bi-directionality especially points to situational specificity. If estimates of true positive and true negative population values are averaged as in standard meta-analysis, validity may be underestimated because of the direct cancellation of effect sizes (Tett et al., as cited in Tett \& Burnett, 2003).

The trend that differences in terms of the strength and direction of personality-job performance relations are evident across situations suggest that situational moderators should be carefully scrutinised (Tett \& Burnett, 2003). The theory of trait activation, for instance, states that if trait-relevant situational cues are present, they will more strongly determine the expression of a trait than the strength of a particular situation (Tett \& Burnett, as cited in Penney et al., 2011).

Situational cues operate at task, social and organisational levels (Tett \& Burnett, as cited in Penney et al., 2011). Tasklevel demands reflect the characteristics of particular job tasks and requirements. Penney et al. (2011) believe that the job demand of emotional labour especially warrants further 
research. Employees facing this demand directly interact with clients and have to adjust their emotional displays based on formal job requirements. The types of interactions that employees typically have with clients may also impact on validity estimates, including positions where employees often encounter negative experiences with clients or the public, as in service positions.

Finally, the duration of employees' relationship with clients or customers may also impact on the validity of the Big Five in predicting job performance. In service relationships, customers and service providers interact continually, whilst service encounters are interactions where customers and service employees typically do not expect interacting in future (Gutek, Bhappu, Liao-Troth \& Cherrym as cited in Penney et al., 2011). The collective impact of being responsive and courteous to customers may particularly play a role in long-term relationships, and traits such as conscientiousness and agreeableness may be particularly important in the performance of employees who maintain service relationships such as those in the CSC context in the banking industry.

\section{Social-level demands}

Barrick, Mount and Judge (as cited in Penney et al., 2011) propose that different personality traits are important in jobs where cooperation with coworkers is necessary, compared to jobs that require competition. Conscientiousness, agreeableness and emotional stability, for instance, imply proper socialisation, indicating a person's ability to be level-headed, self-disciplined and to get along with others (Digman, as cited in Penney et al., 2011).

According to Tett and Burnett (2003), organisational culture and climate serve as some indication of work demands at an organisation level and people will probably perform better in organisations with cultures that match their personality. Other organisational climate variables that may affect the validity of the Big Five traits are work environments that are unfair, complex or stressful.

\section{Trait interactions}

Scholars commonly accept that personality traits do not exist in isolation, but as part of a collection of traits. However, personality-performance relationships have often focused on bivariate relationships between a specific personality facet dimension and core or global job performance (Arthur, Woehr \& Graziano, as cited in Penney et al., 2011). To fully explain job performance, the joint impact of multiple traits should be explored (Hogan, Hogan \& Roberts, as cited in Penney et al., 2011). Despite research demonstrating the validity of the Big Five circumplex (pairs of Big Five traits are presented in circular models, allowing the investigating of intersections between specific trait combinations), few studies have empirically examined the interaction of the Big Five traits in relation to job performance (Judge \& Erez, as cited in Penney et al., 2011).

\section{Trends from research literature}

The validity of the Big Five personality factors in predicting job performance has indeed been evaluated for various job groups such as managerial, sales, customer service, skilled and semi-skilled roles (Barrick \& Mount, as cited in Skyrme et al., 2005).

Support for the use of the Big Five in selection comes from a number of meta-analyses (Barrick, Mount \& Judge, 2001) that have consistently identified relationships between the Big Five and various performance measurements (supervisor ratings, training proficiency, attendance and productivity). For example, Salgado (1997) found that conscientiousness and emotional stability explained $12 \%$ and $7 \%$, respectively, of variance in performance ratings beyond that of cognitive ability (Skyrme et al., 2005). Salgado's (1997) findings demonstrate the usefulness of personality as a selection tool to complement cognitive ability in predicting performance. Salgado (2003) provides further support for the use of the Big Five personality factors in selection. He found that instruments designed around the five-factor model of personality had greater criterion validity than non-five-factor model personality instruments. These two studies underscore the potential usefulness of the Big Five in selection contexts (Skyrme et al., 2005).

In terms of specific dimensions, considerable research found that the five-factor model (FFM) personality dimension of conscientiousness is one of the best predictors of job performance (Salgado, 1997). Conscientiousness tends to be the only personality trait that correlates with performance across all categories of jobs, including CSCs. However, other FFM personality dimensions such as agreeableness and emotional stability may also be important, particularly in jobs that involve a significant degree of social interaction (Mount, Barrick \& Stewart, 1998). Given the nature of CSC work with its emphasis on providing quality customer service, it is likely that the characteristics associated with conscientious individuals (as pointed out earlier) should serve them well when engaging in this type of work.

Skyrme et al. (2005) found that theFFM personality dimensions of conscientiousness, agreeableness and emotional stability were positively related to employee performance. The FFM personality dimension of agreeableness is associated with behaviours such as tolerance, good nature and flexibility (Judge, Higgins, Thoresen \& Barrick, 1999).

Taylor (1998) termed the demands made on call centre staff 'emotional labour', because call agents have to both manage their feelings and attitudes and possess product knowledge. Managing their feelings and attitudes is particularly important in providing suitable levels of service (both in terms of quality and quantity) to enhance customer satisfaction. Skills such as controlling one's feelings are associated with emotional stability; the FFM personality dimension of emotional stability has been positively related to job performance (Mount et al., 1998; Skyrme et al., 2005). 
In terms of the FFM personality dimension of extraversion, Sawyer et al. (2009) found that whether or not staff members are characterised as being extraverted or introverted does not seem to have any bearing on their performance in call centres. Emotionally stable individuals appear to function well in a call centre environment, because they are able to cope with high levels of emotional exhaustion and particularly because they tend not to leave the job. Furthermore, given the restrictive nature of call centres, with scripts and work monitoring, call centre agents who are creative and who seek new experiences (the FFM personality dimension of openness to new experience) may not be well suited to call centre work.

Fort (2010) found facets of conscientiousness, self-reported achievement and dependability to be predictors of job performance, which would be expected since they are components of one broader domain. Similarly, implicit achievement and dependability were also found to be predictors of job performance, suggesting that these two measures may be components of implicit conscientiousness which relates to the FFM personality dimension of conscientiousness. The participants were employees of a contact centre company that provides services to the education industry. Both achievement and dependability have been shown to be related to performance in numerous studies (Dudley, Orvis, Lebiecki \& Cortina, 2006).

Nicholls, Viviers and Visser (2009) found structured and results oriented as moderately strong predictors of performance. Baron, Hill, Janman and Schmidt (1997) report a principal component analysis which showed that structured, results oriented, analytical, detail conscious and conscientious loaded onto the FFM personality dimension of conscientiousness.

Little academic research has been conducted on South African contact centres; most of it focused on agents' behaviour. Nel and De Villiers (2004) found that the job performance of call centre agents was significantly positively related to their emotional intelligence scores. Moller, Crous and Schepers (2004) investigated the personality traits of agents satisfied with call centre work and identified a self-assertive personality type that was dissatisfied with the variety of work available.

The general aim of this study was to determine, firstly, whether personality traits of CSC agents - as measured by the OPQ32r questionnaire - could be expressed in terms of parsimonious personality traits (the Big Five model) and, secondly, whether these dimension-reduced personality traits could be linked to CSC staff members' job performance. In this way, CSC staffs members' personality traits could be used to predict job performance. More specifically, the following research questions guided this research:

- Does the Big Five model of personality traits fit the OPQ32r personality evaluation data of CSC staff members in a particular banking group?

- Does the Big Five personality trait model derived from OPQ32r personality measures impact the performance of CSC staff members as evaluated against their job performance criteria?

\section{Method \\ Research approach}

The study followed the quantitative tradition and was a nonexperimental study. Primary data were used as the researcher gathered all data first-hand. A correlation approach was followed in the data analysis.

\section{Research design}

\section{Research participants}

This research focused on the individual as the unit of analysis. Purposive sampling was used because the entire CSC agent base of the participating banking group, consisting of 89 CSC agents, served as the sample.

The ages of the participants ranged between 20 and 57 years with a mean age of 27 years and a standard deviation of 5.80 years. All participants were proficient in English and 36\% reported English as their home language. Most (98\%) had obtained a Grade 12 or higher qualification, and women made up just over half (57\%) of the sample. In terms of ethnic group, participants were African (52\%), mixed race (14\%), Indian (21\%) and white (2\%). The mean total work experience of the sample was 5.91 years and their mean length of service in their current role was 1.66 years. Upon joining the CSC, agents are required to have basic computer literacy, some experience in using the Internet to assist with Web-based product solution generation and some call centre experience.

\section{Measuring instruments}

Occupational Personality Questionnaire 32r: The OPQ32r was developed based on the trait theory of personality. The OPQ32r uses an occupational model of personality, which describes 32 dimensions or factors of an individual's preferred style of behaviour at work (SHL, 2013).

Even though the OPQ was not developed specifically to fit the FFM model, a subset of the 32 narrowband scales map onto the FFM of personality. The OPQ32r, however, measures a broader personality domain than the FFM. The OPQ32r further measures elements that are not apparent in the Big Five classification such as energy, drive and interests. Applying the FFM allows for validity generalisation and comparison with other personality instruments and previous research findings (Bartram, 2005).

Standardisation of the Occupational Personality Questionnaire 32r: SHL (2013) describes the OPQ32r as an item response theory (IRT)-scored forced-choice version of OPQ32 that measures the same constructs as in earlier versions, but it more efficiently circumvents response bias and score distortion. In an earlier study of bias $(N=13523)$, no practically significant differences were found between cultural and gender groups in South Africa (Joubert \& Venter, 2013). The biggest differences were found between African and white cultural groups, although these differences were mostly small. Only one scale, forward thinking $(d=$ 
0.54), obtained a medium effect size. The effect sizes for the gender comparisons ranged between 0.02 and 0.36 (Joubert \& Venter, 2013).

Visser and Viviers (2010) investigated the construct equivalence of the OPQ32n between black and white people in South Africa. They used structural equation modelling to compare scale inter-correlations between the two groups. The comparison of the covariance matrices indicated a good fit, partially supporting structural equivalence between the two groups. A Comparative Fit Index (CFI) value of 0.942 and a root mean square error of approximation of 0.048 were obtained (Visser \& Viviers, 2010).

To ensure the fairness of OPQ32r scores, group comparison analyses were conducted on several large datasets, including an international general population sample $(N=118324)$. Gender differences were found on a number of scales, but these differences were typically small (SHL, 2013).

Scores across ethnic groups were compared using the OPQ32r UK General Population Norm Sample $(N=22$ 612), but differences, again, were typically small. When scores across different ethnic groups were compared using a US sample $(N=2473)$, the same tendency was evident.

In a study in the USA, UK and the West Indies, the internal consistency of each OPQ scale was determined by calculating Cronbach's coefficient alpha $(N=518)$. The participant group consisted of $68.9 \%$ women and $30.3 \%$ men $(0.8 \%$ did not indicate their gender). Their ages ranged between 18 and 55 years. Only $57 \%$ of the participants indicated their ethnicity. Of these, $36 \%$ were white and $48 \%$ were black. The alpha coefficients ranged between 0.74 and 0.91 (SHL, 2009).

Joubert and Venter (2013) reported South African composite reliabilities on the OPQ32r. The sample consisted of 186 candidates (87 men and 99 women). In terms of ethnic composition, the sample included 59 African, 36 mixed race, 14 Indian and 71 white participants. The reliabilities were comparable with reliabilities found in international studies and ranged from 0.69 to 0.93 with a median reliability of 0.85 .

Considerable evidence supports the validity of the OPQ32, both internationally and locally. Various South African studies, for instance, support both the construct and criterionrelated validity of the OPQ32 (Bartram, Warr \& Brown, as cited in SHL, 2013).

An international concurrent validity study $(N=853)$ was conducted across Europe, Asia Pacific, and North, Central and South America, using the OPQ32r as a predictor of performance in terms of managerial competencies. The median correlation of composite personality predictors was 0.32 for the OPQ32r. Best validities for OPQ32 predictions reach as high as 0.29 (short IRT-scored) for managers, 0.30 (short IRT-scored) for colleagues and 0.27 (short IRT-scored) for direct reports (SHL, 2009).
A number of studies have confirmed the internal and external construct validity of the OPQ32r. In one of these, which included a calibration sample $(N=518)$ and the UK General Population norm sample $(N=22612)$, scale inter-correlations and results of exploratory factor analysis (EFA), for instance, confirmed the normative data structure of the OPQ32r scores (SHL, 2013).

Since the OPQ32r pattern of scale inter-correlations was found to be comparable in other language versions, the 32 constructs may be cross-culturally applicable. When structural equation modelling was used to investigate the level of equivalence in comparing scale inter-correlation matrices of 29 individual countries and regions against those of the UK and US versions of the OPQ32r $(N=118324)$, a high level of construct equivalence was evident (SHL, 2013).

In terms of criterion-related validity, four recent concurrent validation studies showed statistically significant relationships between predicted OPQ32r scales and line managers' ratings of performance. In all these studies, the empirically determined relationships were stronger than non-hypothesised ones. In one study, the OPQ32r was used to predict management competence in a development setting. Data included OPQ32i responses that were re-scored to OPQ32r-equivalent scores and 360-degree ratings of the participant's competencies. OPQ32r composite scores were applied to predict specific leadership competencies and the composite validities were as high as 0.29 for manager ratings, 0.30 for colleagues and 0.27 for direct reports (corrections were not made for range restriction and the possible unreliability of the criterion) (SHL, 2013).

Corporate Executive Board (CEB) (SHL, 2011) developed 92 OPQ32r norms, covering 24 languages and 37 countries. Two of these norms were developed for South Africa: a managerial and professional norm $(N=1267)$ and a general population norm $(N=4880)$. Since then, three OPQ32r norms (a general population norm, a managerial and professional norm and a graduate norm) have been created, derived from data collected from more than 118324 people across 43 countries (including South Africa) and 23 languages (SHL, 2013).

\section{Job performance ratings}

A further measure used in this study was the ratings CSC agents obtained during their bi-annual performance assessment discussion. Agents, as well as their supervisors, determined these ratings, and the following sources were consulted to assess the agent's job performance on their key result areas:

- The customer-interaction quality inspection results: The team leader and agent randomly chose calls and emails on a monthly basis and together analysed them according to certain agreed steps and standards as specified by the checklists used in the organisation. Each CSC agent's bi-annual performance rating on customer-interaction quality was based on the average of these ratings for the particular 6-month period. 
- 360-degree feedback: This type of feedback is used to assess agents' personal, interpersonal and team behaviour. Their rating was based on bi-annual feedback from colleagues, customers and supervisors to ensure objectivity during measurement and to avoid rater errors.

- Balanced Scorecard (BSC) performance ratings: These ratings were based on CSC agents' monthly performances based on the BSC measurements. This performance measurement incorporated the customerinteraction quality inspection results (mentioned earlier) to determine the overall performance rating scale for the individual during the month. The BSC measurement also included financial losses due to agents' negligence, lack of process adherence, and actual call case logging procedures. Each agent's bi-annual performance rating consisted of the average rating that the person obtained during the 6-month period under investigation.

\section{Criterion measures}

The performance appraisal rating was determined by assessing each agent's performance against their key result areas (KRAs), which are determined from CSC agents' outputs as derived from their job description. The following KRAs were used:

- Email or call quality: Call answered immediately, greeting, introduction, client's details captured, addressing customer, handling mistakes, listening, acknowledging, questioning, ensured understanding, problem identification, informing of actions, taking ownership, answering, offering assistance, identifying complaint and escalating call ending.

- Deliver a world-class service and adhere to internal processes and decision tree: Utilising systems and resources effectively, following internal processes, providing reasoning, communicating service level agreement and addressing multiple issues.

- Emails or calls versus cases ratio: Number of calls received compared to the number of reference numbers on system.

- Active team participation: Attendance and participation in recognition, team meetings and training.

- Self-development: Development plan in place, progress on development plan and other achievements indicated on development plan.

- Adhere to and live values: Adherence to company values and rules pertaining to absenteeism, late coming and time management and no disciplinary actions recorded.

The ratings CSC agents obtained in their performance appraisal served as the criterion measure for job performance in this research. A five-point scale was used with descriptions ranging from standards or outcomes not being met (1) to significantly exceeding all outcomes and standards (5). A rating of 3.5 indicates that all outcomes and standards have been met.
The target population of the study was CSC staff members assisting clients at two help desks. The job descriptions, client needs, service requests and staff attributes for both desks are similar. More experienced CSC staff members, however, assist the bank's more discerning clients at help desk 2 .

\section{Research procedure}

Ethical approval for the study was obtained from the higher education institution before the measuring instruments were distributed. The research purpose and intended use of the data were explained to all participating agents and managers. The researcher undertook to assist participants in case any adverse consequences resulted from their participation in the research. The banking group also has an employee wellbeing programme that could provide psychological assistance if necessary.

During the recruitment procedures, participants were informed that they had the right not to participate in the study at all. Furthermore, they could withdraw from the study at any time without any penalty or prejudice. They further had the right to refuse responding to any questions that formed part of an interview or the questionnaire.

The research purpose and intended use of the data were explained to all participating agents and managers. Prior to starting the assessments, all participating CSC agents received an informed consent form that they could complete if they wished to do so.

CSC agents completed the OPQ32 $r$ in paper-and-pencil format. To ensure consistency, the guidelines on the OPQ32r administration card were followed strictly during each test administration session. All participants completed the questionnaire in the same venue and in equally sized groups over 15 consecutive days. In terms of the criterion measure for the research, the CSC agents' supervisors were requested to provide the most recent bi-annual performance rating details for each participant.

On completion, to ensure data protection, the OPQ32r tests were scored by the test developer and are presently (for a period of 3 years) stored in a secure location. Individual results have not been shared with anyone except the participants. Group results have only been shared as explained on the consent form.

To ensure trustworthiness, the reliability and validity of the OPQ and Big Five constructs were determined as discussed in the 'Results' section below.

\section{Statistical analysis strategy}

Exploratory analysis in this study consisted of descriptive statistics calculated for the six sets of job performance rating scores and the 32 sets of OPQ32r personality traits (courtesy SHL). This analysis provided an overview of CSC staff's personality traits and their performance. Correlation matrices were further conducted on the scores of the 32 sets 
of OPQ32r personality score, as well as on the combination of job performance criteria scores (six) and personality trait scores (32), and on the combination of performance criteria scores (six) and the Big Five personality trait scores (courtesy SHL). This analysis served as one way of describing relationships between a CSC agent's personality and their job performance.

EFA was also performed on the correlation matrix of the 32 OPQ32r personality trait scores to determine which personality traits group together to describe broader measures of personality traits such as the Big Five classification. Finally, regression analysis was conducted to describe the nature of established personality-performance relationships in more detail.

\section{Results}

In the sections that follow, general findings on the initial exploratory analysis of the six performance criteria are firstly provided, followed by a corresponding discussion of the 32 personality trait measurements. The discussion of the personality traits (OPQ32r) analysis introduces the idea of a more parsimonious measure of personality characteristics, based on literature in this regard.

The idea of a more parsimonious set of measures of personality traits stems from an exploratory investigation of the $32 \times 32$ correlation matrix of personality trait scores, recommendations from literature and a technical report by SHL (2013) on the Big Five personality characteristics. Preliminary factor analysis investigating the possibility of personality trait dimension-reduction is then discussed. The results of the preliminary, most appropriate factor analysis are consequently compared to literature and the technical report of the SHL OPQ32r (SHL, 2013).

The discussion then focuses on the issue of determining the relationship between personality and performance. This discussion will report on the results of three approaches to investigating possible performance-personality relations. These include (1) deductions derived from the correlation matrix of the scores of the six performance criteria against the scores of the 32 personality traits, (2) deductions derived from the correlation matrix of the scores of the six performance criteria against the scores of five parsimonious measures of personality, namely the Big Five scores and (3) a linear regression between a performance and personality measure that correlate statistically significantly to describe the nature of the relationship in more detail.

Conclusions that can be derived from the analysis results will be briefly discussed, as well as possible explanations for the findings of the empirical research.

\section{Results of exploratory analysis on the six performance criteria and the combined performance criterion}

The rating scale for job performance consisted of a five-point rating scale with a value of ' 1 ' indicating that 'outcomes were not met' and a value of ' 5 ' indicating that 'performance significantly exceeds expected outcome'. As such, the means of the descriptive analysis on these criteria (the summary table on the exploratory analysis is not included in the article) seem overall satisfactory with mean criteria scores (and standard deviations) of 3.57 (0.63), $3.54(0.26), 3.24$ (0.70), $3.59(0.24), 3.44(0.46)$ and $3.44(0.24)$ for the criteria of email and call quality, deliver a world-class service and adhere to internal processes and decision tree, emails or calls versus cases ratio, team participation, self-development and adhere to and live values respectively. These seem to describe a workforce that 'meets all standards'. However, it should be noted that the measures of skewness (and kurtosis) of -0.87 (1.32), 0.24 (4.51), -0.92 (1.02), 1.65 (6.01), -3.18 (13.30) and 0.79 (2.82) for the above criteria indicate that analysis results (still to be discussed) had to be considered carefully. An overall measure of performance was also calculated. The mean value and standard deviation for this measure were 20.83 and 1.30 respectively (with a minimum value of 17.82 and a maximum value of 26.4).

The issue of whether the performance criteria adequately measure performance might be suggested by skewness and kurtosis deviations, as will be discussed in a later section.

\section{Results of analysis on the Occupational Personality Questionnaire 32r personality trait scores and the calculation of parsimonious measures of personality traits: The idea of Big Five measures}

The researchers felt that the 32 mean scores, as reflected in Table 1, did not present an easily interpretable picture of the general personality trait status of the 89 CSC staff members. The researchers therefore considered the idea of reducing the dimensionality of the 32 personality trait measurements into fewer, but more comprehensive, measures of personality characteristics. Initially the 32x32 correlation matrix of personality traits (courtesy SHL) were studied for possible suggestions regarding subsets of traits that group together and which would possibly measure fewer, but more comprehensive, personality traits. As a next step in investigating the possibility of a parsimonious personality trait model, a number of exploratory and tentative factor analyses were conducted on the correlation matrix of the 32 sets of OPQ32r personality trait scores. These analyses were regarded as purely exploratory because the sample size of 89 was quite small in terms of factor analytic standards. This approach followed the argumentation of Barrick et al. (2001), Salgado (1997) and Penney et al. (2011). These results are now briefly discussed.

\section{Exploratory factor analysis}

A few exploratory factor analyses were conducted on the 32-trait personality correlation matrix provided courtesy of SHL. (The factor analyses would be regarded as exploratory or provisional given that the sample size of 89 respondents was relatively small for the purpose of a factor analysis, but these analyses were strictly regarded as another angle to explore the idea of more parsimonious personality measures.) 
TABLE 1: Descriptive statistics of the Occupational Personality Questionnaire 32r and performance criteria.

\begin{tabular}{|c|c|c|c|c|c|c|c|}
\hline OPQ32r scale & Minimum & Maximum & Mean & $\begin{array}{l}\text { Standard } \\
\text { deviation }\end{array}$ & Skewness & Kurtosis & $\begin{array}{l}\text { Composite } \\
\text { reliability }\end{array}$ \\
\hline Persuasive & -1.47 & 2.03 & 0.23 & 0.75 & -0.04 & -0.43 & 0.84 \\
\hline Controlling & -1.02 & 2.10 & 0.37 & 0.65 & 0.39 & -0.15 & 0.93 \\
\hline Outspoken & -1.67 & 1.82 & 0.19 & 0.68 & -0.02 & 0.05 & 0.89 \\
\hline Independent minded & -1.38 & 2.00 & 0.11 & 0.70 & 0.11 & -0.17 & 0.82 \\
\hline Outgoing & -1.50 & 1.77 & 0.28 & 0.73 & -0.05 & -0.16 & 0.91 \\
\hline Affiliative & -1.82 & 1.23 & -0.35 & 0.67 & 0.03 & -0.56 & 0.87 \\
\hline Socially confident & -1.00 & 2.07 & 0.37 & 0.64 & 0.45 & 0.36 & 0.91 \\
\hline Modest & -1.56 & 1.52 & -0.04 & 0.64 & -0.16 & 0.17 & 0.90 \\
\hline Democratic & -1.79 & 1.32 & -0.16 & 0.72 & -0.41 & -0.13 & 0.80 \\
\hline Caring & -2.29 & 1.90 & -0.25 & 0.77 & 0.17 & 0.07 & 0.84 \\
\hline Data rational & -1.67 & 2.05 & 0.34 & 0.80 & 0.10 & -0.16 & 0.90 \\
\hline Evaluative & -1.26 & 1.85 & 0.13 & 0.66 & 0.22 & -0.02 & 0.83 \\
\hline Behavioural & -2.32 & 1.98 & -0.22 & 0.78 & 0.10 & 0.31 & 0.82 \\
\hline Conceptual & -1.29 & 1.99 & 0.20 & 0.65 & 0.25 & 0.03 & 0.84 \\
\hline Innovative & -1.91 & 2.01 & 0.38 & 0.74 & -0.32 & 0.27 & 0.90 \\
\hline Variety seeking & -1.13 & 1.50 & 0.02 & 0.63 & 0.38 & -0.57 & 0.81 \\
\hline Adaptable & -1.90 & 1.56 & -0.24 & 0.77 & -0.19 & -0.61 & 0.90 \\
\hline Forward thinking & -1.75 & 1.29 & 0.10 & 0.58 & -0.29 & 0.04 & 0.87 \\
\hline Detail conscious & -1.54 & 1.89 & 0.11 & 0.76 & 0.09 & -0.61 & 0.90 \\
\hline Conscientious & -1.63 & 1.6 & -0.04 & 0.69 & 0.04 & -0.43 & 0.86 \\
\hline Rule following & -1.87 & 2.00 & -0.08 & 0.80 & -0.04 & -0.14 & 0.91 \\
\hline Relaxed & -1.55 & 1.83 & 0.32 & 0.61 & -0.03 & 0.67 & 0.90 \\
\hline Worrying & -2.21 & 0.59 & -0.69 & 0.63 & -0.12 & -0.51 & 0.90 \\
\hline Tough minded & -1.29 & 2.40 & 0.15 & 0.71 & 0.51 & 0.49 & 0.84 \\
\hline Optimistic & -2.20 & 1.60 & 0.19 & 0.67 & -0.34 & 0.83 & 0.81 \\
\hline Trusting & -1.44 & 1.37 & -0.03 & 0.54 & 0.11 & 0.20 & 0.90 \\
\hline Emotionally controlled & -1.33 & 1.23 & -0.16 & 0.50 & 0.58 & 0.42 & 0.92 \\
\hline Vigorous & -1.91 & 1.47 & 0.14 & 0.65 & -0.48 & 0.70 & 0.91 \\
\hline Achieving & -1.69 & 1.72 & 0.34 & 0.66 & -0.27 & 0.10 & 0.84 \\
\hline Decisive & -1.31 & 2.68 & 0.44 & 0.69 & 0.17 & 0.42 & 0.89 \\
\hline Consistent & 0.65 & 0.89 & 0.77 & 0.05 & -0.25 & -0.72 & - \\
\hline
\end{tabular}

$N=89$.

OPQ32r, Occupational Personality Questionnaire 32r.

Maximum likelihood factor analyses, using a promax rotation, were conducted on the correlation matrix of the scores of the 32 personality traits. Factor analyses with respectively two, three, and up to seven factors extracted in the various models were run. (Analyses were conducted using the Statistical Analysis System software package, version 9.2.)

To motivate the choice of factor analysis model (number of factors extracted) for this study, a summary of various criteria for the seven factor analyses are included in Table 2. Table 2 contains the result of the maximum likelihood factor analysis, with the promax rotation, performed on the correlation matrix of the 32 OPQr personality trait scores.

A comparison of the criteria reported in this table, the scree plot criterion, and the interpretability of the extracted factors all contributed towards the decision of a FFM as model of best fit for the data of the present study.

The model shows that:

- The greatest reduction in the following criteria is regarded as criteria of an appropriate model: the chi- square statistic without Bartlett's correction, the Akaike information criterion, and the Schwarz Basian criterion.

- The Tucker Lewis reliability coefficient which best approaches 1.0 is also regarded as an indicator of a suitable factor model.

- Furthermore, the model that declares the largest proportion of the total of all the eigenvalues measured to the total of eigenvalues included in the factor model also serves as indicator of the most appropriate number of factors to include in the factor model.

- Lastly, the interpretability of the factors generated in the various analyses also serves as guideline as to which model is most appropriate for the study (appropriate number of factors to extract).

The rotated factor pattern for the FFM regarded as most appropriate in this exploratory analysis is presented in Table 3.

Once the issue of the model of best fit was decided, the naming of the factors (describing the more comprehensive personality traits) was guided by comparing the traits within each factor of this analysis to the literature studies mentioned (Bartram \& Brown, 2005; Nyfield, Gibbons, Baron \& Robertson, 1995; 
TABLE 2: Factor analysis criteria for factor analyses with two, three, four, five, six and seven factors extracted.

\begin{tabular}{lllll}
\hline Number of factors & $\begin{array}{l}\text { Proportion of factor } \\
\text { eigenvalues of total } \\
\text { eigenvalues }\end{array}$ & $\begin{array}{l}\text { Chi-square, without } \\
\text { Bartlett }\end{array}$ & $\begin{array}{l}\text { Akaike information } \\
\text { criterion }\end{array}$ & $\begin{array}{l}\text { Schwarz Basian } \\
\text { criterion }\end{array}$ \\
\hline 2 & 0.4562 & 116667.80 & 115801.80 & $\begin{array}{l}\text { Tucker Lewis reliability } \\
\text { coefficient }\end{array}$ \\
\hline 3 & 0.6085 & 92990.45 & 92184.45 & 0.24 \\
4 & 0.7114 & 76930.24 & 76930.24 & 89278.68 \\
\hline 5 & 0.7718 & 67809.88 & 67809.88 & 72945.54 \\
\hline 6 & 0.8245 & 60307.92 & 60307.92 & 64623.10 \\
\hline
\end{tabular}

Maximum likelihood factor analyses, with the promax rotation, were performed on the correlation matrix of the Occupational Personality Questionnaire 32r personality trait scores. $\dagger$, Conversion criteria for iterative analysis not satisfied.

TABLE 3: Rotated factor pattern (standardised regression coefficients) for five-factor model (maximum likelihood with promax rotation).

\begin{tabular}{|c|c|c|c|c|c|}
\hline OPQ32r scale & Factor 1 & Factor 2 & Factor 3 & Factor 4 & Factor 5 \\
\hline Detail conscious & $80 *$ & 8 & 17 & -10 & 2 \\
\hline Rule following & $80 *$ & -11 & -4 & 1 & 8 \\
\hline Conscientious & $69 *$ & 6 & 19 & -1 & 20 \\
\hline Conventional & $59 *$ & -12 & -19 & -7 & -3 \\
\hline Vigorous & $53 *$ & -3 & 13 & -1 & -12 \\
\hline Independent minded & $-42^{*}$ & 7 & 16 & -21 & 6 \\
\hline Variety seeking & $-52^{*}$ & 4 & 14 & -12 & 5 \\
\hline Competitive & 0 & $71 *$ & -7 & $-46 *$ & -19 \\
\hline Outgoing & -6 & $70 *$ & -25 & 15 & -1 \\
\hline Persuasive & -6 & $56^{*}$ & 15 & -15 & 3 \\
\hline Socially confident & 4 & $56 *$ & 6 & 18 & $48^{*}$ \\
\hline Outspoken & -3 & $45^{*}$ & -2 & 1 & 29 \\
\hline Controlling & -4 & $45^{*}$ & 30 & -4 & 24 \\
\hline Modest & 6 & $-49 *$ & -24 & -13 & 25 \\
\hline Innovative & -21 & 16 & $63 *$ & -2 & 4 \\
\hline Achieving & 22 & 34 & $58^{*}$ & 1 & -14 \\
\hline Conceptual & -19 & -23 & $53 *$ & 24 & 30 \\
\hline Forward thinking & -1 & 11 & $53 *$ & 29 & -27 \\
\hline Data rational & 7 & -7 & $42^{*}$ & -24 & 21 \\
\hline Behavioural & -8 & -7 & 19 & $75^{*}$ & 17 \\
\hline Caring & 21 & -3 & -15 & $65^{*}$ & 25 \\
\hline Affiliative & -3 & $46 *$ & $-40^{*}$ & $49 *$ & 17 \\
\hline Democratic & 20 & -14 & 14 & $46^{*}$ & -15 \\
\hline Optimistic & 27 & 15 & 14 & $42 *$ & -5 \\
\hline Trusting & -15 & 2 & -3 & $38(40)^{*}$ & 6 \\
\hline Decisive & -17 & 21 & 13 & -27 & 21 \\
\hline Tough minded & -13 & -4 & 5 & 9 & $57^{*}$ \\
\hline Relaxed & 6 & -4 & -12 & 18 & $43^{*}$ \\
\hline Worrying & -3 & -17 & -16 & 4 & $-75 *$ \\
\hline
\end{tabular}

Printed values are multiplied by 100 and rounded to the nearest integer OPQ32r, Occupational Personality Questionnaire 32r.

*, Greater than 0.4

Visser \& Du Toit, 2004) and results on the Big Five model discussed in the SHL OPQ32r technical manual (SHL, 2013). A comparative table is presented in Table 4.

It was argued that if agreement between subsets of personality traits of the above factor analysis could be established with the literature and the SHL OPQ32r technical report, such correspondence would confirm the idea of composite personality trait measures. It was argued that positive findings in this regard would justify the use of composite personality measures similar to the Big Five measures. Table 4 reports on the comparison between the factors of the three literature references, the OPQ32r technical report and the tentative fivefactor analysis findings of the service desk study.

The subsets of personality traits identified in the present study generally correspond to the Big Five dimensions identified in literature. The comparison also indicates good agreement with the OPQ32r Big Five. Personality traits that were included in any of these factors in the present study which seemed to differ from the SHL report are indicated in bold italics. Closer inspection of the correlation matrix of the 32 personality trait scores indicated that statistically significant correlations between these mentioned service desk personality traits and OPQ32r personality traits of the 
TABLE 4: Comparison of the sets of personality traits of the Big Five factors to literature references - the SHL Occupational Personality Questionnaire 32r technical report and the five-factor model calculated for the service desk data.

\begin{tabular}{|c|c|c|c|c|c|c|}
\hline Big Five & $\begin{array}{l}\text { OPQ 32r (Bartram \& } \\
\text { Brown, 2005) }\end{array}$ & $\begin{array}{l}\text { Visser \& Du Toit } \\
\text { (2004) and Nyfield } \\
\text { et al. (1995) }\end{array}$ & $\begin{array}{l}\text { Visser \& Du Toit } \\
\text { (2004) and Matthews } \\
\text { et al. (1990) }\end{array}$ & $\begin{array}{l}\text { Joubert \& Venter } \\
\text { (2013) }\end{array}$ & SHL $(2009$, p. 34) & $\begin{array}{l}\text { Maximum likelihood } \\
\text { and Promax rotation }\end{array}$ \\
\hline \multirow[t]{8}{*}{ Extraversion } & Outgoing & Outgoing & Outgoing & Outgoing & Outgoing & Outgoing \\
\hline & Affliative & Affiliative & Affiliative & Affiliative & Affiliative & Socially confident? \\
\hline & Emotionally controlled $\dagger$ & Emotionally controlled $\dagger$ & Emotionally controlled $\dagger$ & Emotionally controlled $\dagger$ & Emotionally controlled $\dagger$ & Controlling \\
\hline & Socially confident & - & Socially confident & Socially confident & Socially confident & Persuasive \\
\hline & Controlling & - & Controlling & Controlling & Controlling & Outspoken \\
\hline & Persuasive & - & - & Persuasive & Persuasive & Modest $\dagger$ \\
\hline & - & - & - & - & Outspoken & Competitive? \\
\hline & - & - & - & - & Modest $\dagger$ & - \\
\hline \multirow[t]{8}{*}{ Agreeable } & Caring & Caring & Caring & Caring & Caring & Caring \\
\hline & Democratic & Democratic & Democratic & Democratic & Democratic & Democratic \\
\hline & Competitive $\dagger$ & Competitive $\dagger$ & Competitive $\dagger$ & Competitive $\dagger$ & Competitive $\dagger$ & Trusting \\
\hline & Independent minded $\dagger$ & - & Independent minded $\dagger$ & Trusting & Independent minded $\dagger$ & Affiliative? \\
\hline & Trusting & - & Achieving $\dagger$ & Independent minded $\dagger$ & Trusting & Behavioural \\
\hline & - & - & Critical $\dagger$ & Outspoken $\dagger$ & Affiliative & Optimistic \\
\hline & - & - & Modest & - & Behavioural & - \\
\hline & - & - & - & - & Decisive $\dagger$ & - \\
\hline \multirow[t]{7}{*}{ Conscientious } & Conscientious & Conscientious & Conscientious & Conscientious & Conscientious & Conscientious \\
\hline & Detail conscious & Detail conscious & Detail conscious & Detail conscious & Detail conscious & Detail conscious \\
\hline & Forward thinking & Forward planning & Forward planning & Forward thinking & Forward thinking & Vigorous \\
\hline & Achieving & - & Socially desirable & Achieving & Achieving & Conventional \\
\hline & Vigorous & - & - & Vigorous & Vigorous & $\begin{array}{l}\text { Rule following } \\
\text { (conscientious and data } \\
\text { conscious) }\end{array}$ \\
\hline & - & - & - & - & Controlling & $\begin{array}{l}\text { Independent minded } \\
\text { (detail conscious) }\end{array}$ \\
\hline & - & - & - & - & Evaluative & $\begin{array}{l}\text { Variety seeking (detail } \\
\text { conscious, }\end{array}$ \\
\hline \multirow[t]{8}{*}{ Emotionally stable } & Worrying $\dagger$ & Worrying $\dagger$ & Worrying $\dagger$ & Worrying $\dagger$ & Worrying $\dagger$ & Tough minded \\
\hline & Relaxed & Relaxed & Relaxed & Relaxed & Relaxed & Relaxed \\
\hline & Tough minded & Tough minded & Tough minded & Tough minded & Tough minded & Worrying $\dagger$ \\
\hline & Optimistic & Optimistic & Optimistic & Optimistic & Optimistic & - \\
\hline & Socially confident & - & - & Socially confident & Socially confident & - \\
\hline & - & - & - & - & Adaptable $\dagger$ & - \\
\hline & - & - & - & - & Optimistic & - \\
\hline & - & - & - & - & Trusting & - \\
\hline \multirow[t]{10}{*}{ Openness } & Innovative & Innovative & Innovative & Innovative & Data rational & Innovative \\
\hline & Conventional $\dagger$ & Conceptual & Artistic & Conventional $\dagger$ & Evaluative & Conceptual \\
\hline & Conceptual & Artistic & Behavioural & Conceptual & Conceptual & Data rational \\
\hline & Variety seeking & Behavioural & Independent & Behavioural & Persuasive & Evaluative \\
\hline & Behavioural & - & - & Variety seeking & Independent minded & $\begin{array}{l}\text { Forward thinking } \\
\text { (evaluative) }\end{array}$ \\
\hline & - & - & - & - & Behavioural & $\begin{array}{l}\text { Achieving (data rational, } \\
\text { evaluative, innovative, } \\
\text { rule following) }\end{array}$ \\
\hline & - & - & - & - & Conventional $\dagger$ & - \\
\hline & - & - & - & - & Conceptual & - \\
\hline & - & - & - & - & Variety seeking & - \\
\hline & - & - & - & - & Rule following $\dagger$ & - \\
\hline
\end{tabular}

Note: Please see the full reference list of the article, Blignaut, L., \& Ungerer, L.M. (2014). Personality as predictor of customer service centre agent performance in the banking industry: An exploratory study. SA Journal of Human Resource Management/SA Tydskrif vir Menslikehulpbronbestuur, 12(1), Art. \#607, 16 pages. http://dx.doi.org/10.4102/sajhrm.v12i1.607, for more information. OPQ32r, Occupational Personality Questionnaire 32r.

$\dagger$, indicates a negative correlation.

Big Five factors could be verified. The personality traits that correlate with the OPQ32r Big Five personality traits appear in bracketed italics.

The EFA thus served to establish personality trait measures that are more parsimonious that the original 32 personality measures and verified agreement between Big Five personality measures of independent studies and OPQ32r with the results of the present study.

\section{Relationship between performance criteria, personality trait scores and Big Five personality trait scores}

The applicability of the Big Five personality measures for this study was thus confirmed. The relationship between, firstly, the six performance criteria and the Big Five personality traits and, secondly, between the performance criteria and the 32 personality traits were next investigated by means of 


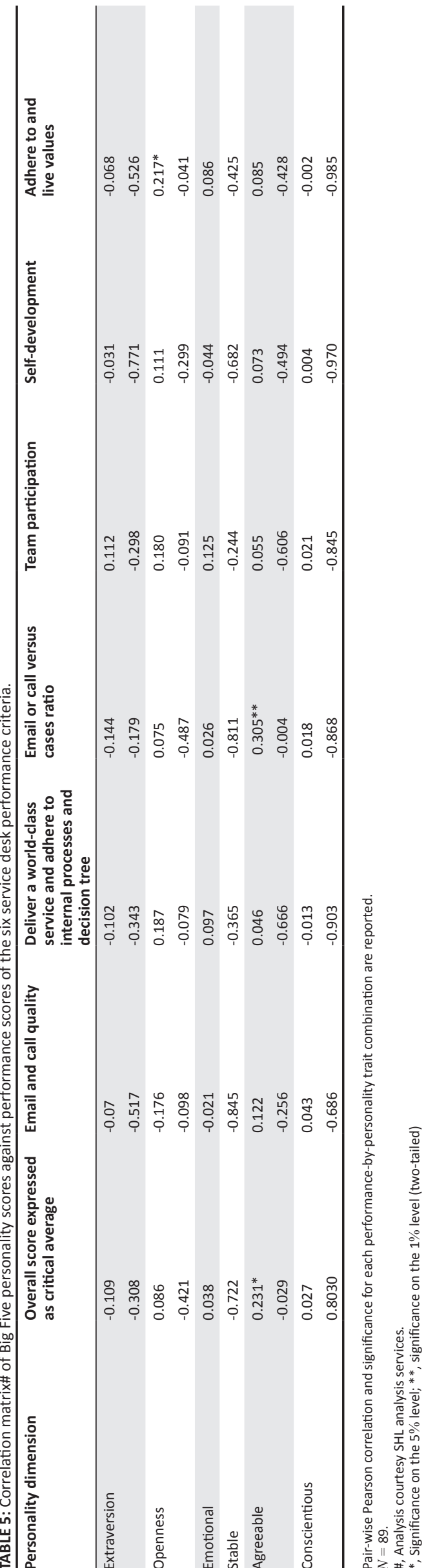

correlation matrices to investigate personality-performance relations and dependency.

Analysis provided by SHL, which included the correlation matrix of the scores of the performance criteria measures (six criteria) against the scores of the 32 personality trait measures, served as initial indicator of personalityperformance relationships. However, comparison of the $32 \times 6$ correlation coefficients became unwieldy and somewhat confusing (the matrix is not included in this article). This situation again strengthened the conviction that composite personality measures, such as the established (although tentatively) Big Five personality measures for this study, would provide a more readily interpretable picture of the personality-performance relationship issue. Table 5 presents the correlation matrix of the six performance criteria against the Big Five personality trait scores (courtesy SHL).

\section{Deductions regarding performance-personality relationships and dependencies}

Of particular interest in Table 5 is the fact that a statistically significant relationship is reported between emails or calls versus cases ratio and the Big Five personality trait of agreeableness. A statistically significant relationship between the performance criterion of adhere to and live values and the Big Five personality trait of openness is also reported. A general measure of performance (reported in Table 5) was additionally calculated to investigate whether a combined measure of performance would more effectively describe the relationship between performance and Big Five personality traits, as recommended by Judge, Heller and Mount (cited in Penney et al., 2011). However, statistical significance was only reported for the relationship between the Big Five personality trait of agreeableness and the overall performance score. Agreeableness therefore seems to be the composite personality trait that predicts performance, and more specifically emails or calls versus cases ratio. The nature of the relationship between the performance criterion of emails or calls versus cases ratio and the Big Five personality trait of agreeableness was further investigated in a regression analysis. (Similar regression analyses that were performed on the remaining performance criteria scores proved to be non-significant and these analyses are not reported on.) The results confirm the statistical significance of the agreeable personality trait on emails or calls versus cases ratio performance score, and furthermore describe a positive relationship (slope $=0.22$ ) between agreeableness and emails or calls versus cases ratio performance. However, only $8 \%$ (adjusted $R$-squared value of 0.08 ) of the total variation in the data was explained by this relation.

\section{Discussion}

The aim of this study was to determine whether OPQ32r personality traits of CSC staff can be expressed in terms of the Big Five personality traits, whether personalityperformance relationships can be identified (by means of the 
TABLE 6: Linear regression\# of Big Five agreeable personality trait (independent variable) scores on emails and calls versus cases ration performance scores (dependant variable).

\begin{tabular}{|c|c|c|c|c|c|c|c|c|c|}
\hline Results & $\begin{array}{l}\text { Sum of } \\
\text { squares }\end{array}$ & $d f$ & $\begin{array}{l}\text { Mean sum } \\
\text { of square }\end{array}$ & $F$ statistic & $\begin{array}{l}\text { Probability } \\
\text { ( } F \text { statistic } \\
\text { value) }\end{array}$ & Coefficient & $\begin{array}{l}\text { Standard } \\
\text { deviation }\end{array}$ & $t$-statistic & $\begin{array}{l}\text { Probability } \\
\text { ( } t \text {-statistic } \\
\text { value) }\end{array}$ \\
\hline Regression & 3.95 & 1 & 3.95 & 8.89 & 0.004 & - & - & - & - \\
\hline Total & 42.63 & 88 & - & - & - & - & - & - & - \\
\hline Constant & - & - & - & - & - & 2.13 & 0.38 & 5.61 & $<0.0001$ \\
\hline Big Five agreement & - & - & - & - & - & 0.22 & 0.07 & 2.98 & 0.004 \\
\hline
\end{tabular}

Regression coefficients of the linear regression (Adjusted $R$-squared $=0.08$ ).

$d f$, degrees of freedom.

\#, Analysis courtesy SHL analysis services (initially part of step-wise regression analysis with only one Big Five component statistically significant).

Big Five personality traits and performance criteria set by the particular banking group) for CSC agents and whether these relationships can be applied in predicting CSC agents' job performance according to their personality traits.

A number of researchers (Fort, 2010; Nicholls et al., 2009; Salgado, 1997; Skyrme et al., 2005) found that the FFM personality dimension of conscientiousness is one of the best predictors of job performance. This finding was not replicated in the current study.

As indicated earlier, Sawyer et al. (2009) found that the fact that an individual is extraverted or introverted did not have any bearing on performance in call centres. This finding was replicated in the current study since no statistically significant relationship between the Big Five personality trait of extraversion and performance criteria was reported in this study.

Sawyer et al. (2009) found that emotionally stable individuals appear to function well in a call centre environment, because they are able to cope with high levels of emotional exhaustion and seem to have lower turnover rates. Skyrme et al. (2005) found the FFM personality dimension of emotional stability to be a significant predictor of job performance. This finding was not replicated in the current study: no statistically significant relationship between emotional stability and performance criterion was reported.

Skyrme et al. (2005) and Judge et al. (1999) further found that the FFM personality dimension of agreeableness was positively related to employee performance. This finding was indeed replicated in the current study.

Sawyer et al. (2009) also found that given the restrictive nature of call centres, with scripts and work monitoring, those individuals who are creative and who seek new experiences (the FFM personality dimension of openness to new experience) may not be suited for call centre work. An indication of such a trend was reported for this study with a statistically significant correlation coefficient $(0.22)$ reported between openness and adhere to and live values scores. (The score values of the adhere to and live values performance criterion were, however, highly centralised, with a standard deviation of 0.24 ; this relationship was not investigated further.) This finding was thus replicated in the current study.

\section{Conclusion}

The question might be raised why stronger indications of relationships between performance and personality were not found in the present study. On the one hand, the applicability of the Big Five factors as personality measures was extensively investigated and these personality measures appear to be appropriate measures of personality in this study. On the other hand, however, the performance criteria used in this study appear to be problematic. The job performance criteria used to measure CSC agents' success may not appropriately measure job performance in this context. CSC agents' job performance may not have been measured correctly, the criteria may not measure critical performance aspects in a CSC context in the banking industry, and it may have been advisable to more intensively consider situational specificity (Tett \& Burnett, 2003).

Significant levels of skewness and kurtosis were further reported for some of the performance criteria: selfdevelopment exhibited both excessive kurtosis (13.30) and skewness (-3.18), whilst the deliver a world-class service criterion and team participation exhibited excessive kurtosis (4.51 and 6.01 respectively). Although kurtosis is sample size dependent, the excessive kurtosis and skewness could signal that the performance measures and the way evaluation is conducted require further investigation.

\section{Limitations of the study}

Since such a limited sample was used, findings may not be generalisable across the banking industry. The CSC agents who participated in this study further comprised only one job family and, thus, generalising results beyond this population would be questionable.

An implicit assumption in research using self-report surveys, as in the current study, is that respondents provide accurate responses. An inherent limitation of self-report surveys, however, is that this may not be the case. The possibility of bias in personality trait evaluation for both the OPQ32r and Big Five traits therefore always exists. The relatively small sample size $(N=89)$ and the possibility that the performance criteria could potentially be weak may further have influenced the analysis results.

The cross-sectional research design limits the possibility of drawing conclusions about the causal nature of the 
relationships. Because this study was exploratory in nature and involved only a purposive sample of participants (representing the target population from a particular banking group) the generalisation of findings to the broader banking industry may be limited.

A final concern that presents in virtually all studies that investigate job performance as an outcome is the issue of range restriction. Only a limited number of applicants will be appointed. As the entire population served as the sample, it was not possible to compare standard deviations within the sample against those of the normal population to correct the analysis for attenuation if needed. The absence of information on applicants that were not selected for a particular position tends to reduce the distribution and the identified effect sizes will probably be lower than population effect sizes. Considering this trend, the correlations reported in this study may be attenuated (O'Boyle, Humphrey, Pollack, Hawver \& Story, 2011).

\section{Recommendations for future research}

A number of areas for future research emanate from the present study. Further investigation of personality traits (as measured by the OPQ32r) that may act as job performance predictors for CSC agents in the banking industry appears warranted. It would, however, be advisable to employ larger sample sizes than in the current study.

The measures of job performance in the current study mainly focused on task performance. A more holistic view of the job performance of CSC agents in the banking industry in future research may result in a more nuanced understanding of the relations between their personality traits and job performance.

Penney et al.'s (2011) recommendation that the job criterion domain should be expanded to include internal and external service-oriented behaviour, as well as adaptive performance, may be particularly relevant in a service environment. It may be worthwhile investigating whether the degree of emotional labour or the duration of client relationships affect the validity of the Big Five traits in a CSC context in the banking industry.

The validity of personality traits in predicting job performance may not only be affected by the external work environment, but also by an individual's other personality traits. Investigating the interaction amongst traits instead of merely focusing on main effects may considerably improve the ability to predict job performance. Penney et al. (2011) further recommend research investigating whether the personality composition of workgroups is related to other dimensions of individual and group performance.

Tett and Burnett (2003) believe it to be commendable to apply the Big Five in classifying validities according to job and trait categories. Situational specificity, however, may play a part in these categories. The nature of work situations and the psychological processes mediating trait-performance linkages therefore have to be considered in more depth.
Finally, since the expression of traits in job-related behaviour depends on situational cues, Penney et al. (2011) recommend the development of a comprehensive taxonomy of situational factors that may impact on the personality-performance relationship (including the validity of the Big Five traits) in predicting job performance.

\section{Acknowledgements Competing interests}

The authors declare that they have no financial or personal relationship(s) that may have inappropriately influenced them in writing this article.

\section{Authors' contributions}

L.B. (University of South Africa) conducted this research in partial fulfilment of a MCom degree. L.M.U. (University of South Africa) was the supervisor. Both L.B. and L.M.U. wrote the article.

\section{References}

Adria, M., \& Chowdhury, S. (2004). Centralization as a design consideration for the management of call centres. Information and Management, 41, 497-507. http:// dx.doi.org/10.1016/S0378-7206(03)00087-9

Barnes, P. (2001). People problems in call centres. Management Services, 45(7), 3031.

Baron, H., Hill, S., Janman, K., \& Schmidt, S. (1997). Customer contact manual and user's guide. Surrey, UK: SHL.

Barrick, M.R., \& Mount, M.K. (1991). The Big Five personality dimensions and job performance: A meta-analysis. Personnel Psychology, 44, 1-26. http://dx.doi. org/10.1111/j.1744-6570.1991.tb00688.x

Barrick, M.R., Mount, M.K., \& Judge, T.A. (2001). Personality and performance at the beginning of the new millenium: What do we know and where do we go next? International Journal of Selection and Assessment, 9, 9-30. http://dx.doi. org/10.1111/1468-2389.00160

Bartram, D. (2005). The great eight competencies: A criterion-centric approach to validation. Journal of Applied Psychology, 90(6), 1185-1203. http://dx.doi. org/10.1037/0021-9010.90.6.1185

Bartram, D., \& Brown, A. (2005). Five factor model (Big Five) OPQ32 report: OPQ32 Technical manual supplement. Thames Ditton, Surrey, UK: SHL Group.

Campbell, J.P. (1990). Modelling the performance prediction problem in industrial and organizational psychology. In M.D. Dunnette, \& L.M. Hough (Eds.), Handbook of
industrial and organizational psychology (2nd edn.) (pp. 687-731). Palo Alto, CA: industrial and organizational psych
Consulting Psychologists Press.

Dudley, N.M., Orvis, K.A., Lebiecki, J.E., \& Cortina, J.M. (2006). A meta-analytic investigation of conscientiousness in the prediction of job performance: Examining the intercorrelations and the incremental validity of narrow traits. Journal of Applied Psychology, 91, 40-57. http://dx.doi.org/10.1037/0021-9010.91.1.40

Fort, T.R. (2010). Personality predictors of job performance: Implicit association tests versus self-report measures. Doctoral thesis, Department of Psychology, Walden University, Minneapolis, USA.

Haenlein, M., Kaplan, A.M., \& Beeser, A.J. (2007). A model to determine customer lifetime value in a retail banking context. European Management Journal, 25(3), 221-234. http://dx.doi.org/10.1016/j.emj.2007.01.004

Hogan, R., Hogan, J., \& Roberts, B.W. (1996). Personality measurement and employment decisions: Questions and answers. American Psychologist, 51, 469477. http://dx.doi.org/10.1037/0003-066X.51.5.469

Huysamen, G.K. (2002). The relevance of the new APA standards for educational and psychological testing for employment testing in South Africa. South African Journal of Psychology, 32(2), 26-33. http://dx.doi.org/10.1177/008124630203200203

Janse van Rensburg, Y., Boonzaier, B., \& Boonzaier, M. (2013). The job demandsresources model of work engagement in South African call centres. SA Journal of Human Resource Management/SA Tydskrif vir Menslikehulpbronbestuur, 11(1), Art. \#484, 13 pages. http://dx.doi.org/10.4102/ sajhrm.v11i1.484

Joubert, T., \& Venter, N. (2013). Occupational Personality Questionnaire (OPQ). In S. Laher, \& K. Cockcroft (Eds.), Psychological assessment in South Africa: Research and applications (pp. 277-291). Johannesburg, South Africa: Wits University Press.

Judge, T.A., Heller, D., \& Mount, M.K. (2002). Five-factor model of personality and job satisfaction: A meta-analysis. Journal of Applied Psychology, 87, 530-541. http:// dx.doi.org/10.1037/0021-9010.87.3.530

Judge, T.A., Higgins, C.A., Thoresen, C.J., \& Barrick, M.R. (1999). The Big Five personality traits, general mental ability, and career success across the life span. Personne Psychology, 52(3), 621-652. http://dx.doi.org/10.1111/j.1744-6570.1999. tb00174.x 
Ladhari, R. (2009). Assessment of the psychometric properties of SERVQUAL in the Canadian banking industry. Journal of Financial Services Marketing, 14(1), 70-82. http://dx.doi.org/10.1057/fsm.2009.2

Langley, S., Fjalestad, E., Fichtner, B., \& Hart, M. (2006). Contact centre performance: In pursuit of first call resolution. Management Dynamics: Journal of the Southern African Institute for Management Scientists, 15(4), 17-28.

Matthews, G., Stanton, N., Graham, N.C., \& Brimelow, C. (1990). A factor analysis of the scales of the Occupational Personality Questionnaire. Personality and Individual Differences, 11(6), 591-596. http://dx.doi.org/10.1016/0191-8869(90)90042-P

Mattila, A.S., \& Mount, D.J. (2003). The role of call centres in mollifying disgruntled guests. Cornell Hotel and Restaurant Administration Quarterly, 44(4), 142-150.

Merchants. (2006). Merchants global contact centre benchmarking summary report 2006. South Africa: Dimension Data.

Moller, Y., Crous, F., \& Schepers, J.M. (2004). 'n Ondersoek na die persoonlikheidseienskappe van inbelsentrumkonsultante [An investigation into the personality characteristics of call centre consultants]. South African Journal of Industrial Psychology, 30(2), 74-84.

Motowidlo, S.J. (2003). Job performance. In W. Borman, D. Ilgen, \& R. Klimoski (Eds.) Handbook of Psychology 12 (pp. 39-53). Hoboken, NJ: John Wiley and Sons, Inc. http://dx.doi.org/10.1002/0471264385.wei1203

Motowildo, S.J., Borman, W.C. \& Schmit, M. (1997). A theory of individual differences in task and contextual performance. Human Performance, 10(2), 71-83. http:// dx.doi.org/10.1207/s15327043hup1002 1

Mount, M.K., Barrick, M.R., \& Stewart, G.L. (1998). Five-factor model of personality and performance in jobs involving interpersonal interactions. Human Performance, 11, 145-165. http://dx.doi.org/10.1080/08959285.1998.9668029

Nel, H., \& De Villiers, W.S. (2004). The relationship between emotional intelligence and job performance in a call centre environment. South African Journal of Industrial Psychology, 30(3), 75-81.

Nicholls, M., Viviers, A.M., \& Visser, D. (2009). Validation of a test battery for the selection of call centre operators in a communications company. South African Journal of Psychology, 39(1), 19-31. http://dx.doi.org/10.1177/008124630903900102

Nyfield, G., Gibbons, J.P., Baron, H., \& Robertson, I. (1995). The cross-cultural validity of management assessment methods. Surrey, UK: Saville \& Holdsworth.

O’Boyle, E.H., Humphrey, R.H., Pollack, J.M., Hawver, T.H., \& Story, P.A. (2011). The relation between emotional intelligence and job performance: A meta-analysis. Journal of Organizational Behaviour, 32(5), 788-818. http://dx.doi.org/10.1002/ job.714

O'Hara, A. (2001). How to develop a retention-orientated agent recruiting and selection process. In Call centre recruiting and new hire training: The best of al call center management review (pp. 21-25). Annapolis, MD: Call Centre Press.

Ones, D.S., Dilchert, S., Viswesvaran, C., \& Judge, T.A. (2007). In support of personality assessment in organizational settings. Personnel Psychology, 60(4), 995-1027. $\mathrm{http}: / / d x . d o i . o r g / 10.1111 / \mathrm{j} .1744-6570.2007 .00099 . x$
Penney, L.M., David, E., \& Witt, L.A. (2011). A review of personality and performance: Identifying boundaries, contingencies, and future research directions. Human Resource Management Review, 21(4), 297-310. http://dx.doi.org/10.1016/j. Resource Managem
hrmr.2010.10.005

Rothstein, M.G., \& Goffin, R.D. (2006). The use of personality measures in personnel selection: What does current research support? Human Resource Management Review, 16(2), 155-180. http://dx.doi.org/10.1016/j.hrmr.2006.03.004

Salgado, J.F. (1997). The five factor model of personality and job performance in the European community. Journal of Applied Psychology, 82(1), 30-43. http://dx.doi. org/10.1037/0021-9010.82.1.30

Salgado, J.F. (2003). Predicting job performance using FFM and non-FFM personality measures. Journal of Occupational and Organizational Psychology, 76(3), 323346. http://dx.doi.org/10.1348/096317903769647201

Sawyer, O.O., Srinivas, S., \& Wang, S. (2009). Call centre employee personality factors and service performance. Journal of Services Marketing, 23(5), 301-307. http:// dx.doi.org/10.1108/08876040910973413

SHL. (2009). Development and psychometric properties of OPQ32r. Supplement to the OPQ32 technical manual. UK: SHL Group plc.

SHL. (2011). OPQ32r technical manual. Thames Ditton, UK: SHL Group plc.

SHL. (2013). OPQ32r technical manual. Thames Ditton, UK: SHL Group Ltd.

Skyrme, P., Wilkinson, L., Abraham, J.D., \& Morrison, J.D. (2005). Using personality to predict outbound call centre job performance. Applied HRM Research, 10(2), 89-98.

Subramaniam, L.V. (2008). Call centres of the future. I.T. magazine, 48-51. Retrieved May 29, 2011, from http://lvs004.googlepages.com/callcentres.pdf

Taylor, S. (1998). Emotional labour and the new workplace. In P. Thompson, \& C Wurhurst (Eds.), Workplaces of the future (pp. 84-103). London, UK: Macmillan.

Tett, R.P., \& Burnett, D.D. (2003). A personality trait-based interactionist model of job performance. Journal of Applied Psychology, 88(3), 500-517. http://dx.doi. org/10.1037/0021-9010.88.3.500

Tett, R.P., \& Christiansen, N.D. (2007). Personality tests at the crossroads: A response to Morgeson, Campion, Dipboye, Hollenbeck, Murphy, and Schmitt (2007). Personnel Psychology, 60(4), 967-993. http://dx.doi.org/10.1111/j.17446570.2007.00098.x

Van der Linden, D., Te Nijenhuis, J., \& Bakker, A.B. (2010). The general factor of personality: A meta-analysis of Big Five intercorrelations and a criterion-related validity study. Journal of Research in Personality, 44(3), 315-327. http://dx.doi. org/10.1016/j.jrp.2010.03.003

Visser, D., \& Du Toit, J. (2004). Using the occupational personality questionnaire (OPQ for measuring broad traits. SA Journal of Industrial Psychology, 30(4). http:// dx.doi.org/10.4102/sajip.v30i4.176

Visser, D., \& Viviers, R. (2010). Construct equivalence of the OPQ32n for Black and White people in South Africa. SA Journal of Industrial Psychology, 36(1), 11 pages. http://dx.doi.org/10.4102/sajip.v36i1.748 